Rev. Bras. Ciêric. Vet. 1(1):01-05, set. /dez. 1994

\title{
Clostrídios em condimentos utilizados em embutidos cárneos
}

\section{(Clostridium of vegetable spices utilized in sausages)}

\author{
OLIVEIRA, Luiz A. Trindade de*, FRANCO, Robson M.**, e CARVALHO, José C. A. do Prado***
}

\begin{abstract}
Resumo
Em 35 amostras de diferentes condimentos vegetais, utilizados em embutidos cárneos, conforme metodologia recomendada por Holdeman et al. (1977) e Jürgensen e Jürgensen (1982) foram isolados microrganismos do gênero Clostridium. Nas análises efetuadas comprovamos a presença de clostrídios em $65,7 \%$ do total de amostras analisadas. Foram isolados, pelas características fenotípicas identificadas, os seguintes microrganismos nas amostras correspondentes: Pimenta branca (Clostridium glycolicum, Clostridium butyricum, Clostridium perfringens): Louro (Clostridium perfringens); Canelà (Clostridium perfringens); Noz-moscada (Clostridium perfringens, clostridium ramosum): Cominho (Clostridium perene, Clostridium glycolicum, Clostridium barati); Alho (Clostridium perene, Clostridium perfringens); Cebola (Clostridium glycolicum, Clostridium paraputrificum, Clostridium perfringens); Orégano (Clostridium acetobutylicum, Clostridium glycolicum, Clostridium ramosum): Coentro (Clostridium perfringens, Clostridium glycolicum); Pimenta preta (Clostridium felsineum, Clostridium sporogenes).
\end{abstract}

Palavras chave: Clostrídios, Especiarias, Embutidos Cárneos

\section{Introdução}

A adição de condimentos aos produtos cárneos embutidos, tomando-se por base o artigo 412 do Regulamento de Inspeção Industrial e Sanitária de Produtos de Origem Animal RIISPOA, (1952) é um fato rotineiro da indústria de alimentos e não é de surpreender, que devido a expansão industrial ocorra um crescimento cada vez maior do emprego destes ingredientes, sejam eles de caráter artificial ou natural.

Os microrganismos necessitam de nutrientes e condições físico-químicas adequadas para o seu desenvolvimento, tais como: atividade de água do meio ambiente (alimento), pH, potencial de óxido-redução (Eh), que reunidas condicionam o seu "habitat". Os condimentos vegetais podem conter óleos ou gorduras que estão sujeitos a sofrerem hidrólise ou oxidação, e quantidade de água suficiente que podem permitir a presença de microrganismos.

Finegold (1977) cita Loesche (1969) que classifica os organismos anaeróbios como: anaeróbios estritos (crescimento máximo $\mathrm{PO}_{2}<0,5 \%$ ); anaeróbios moderados (crescimento máximo a $\mathrm{PO}_{2}<3 \%$ ) e microaerófilos (crescimento máximo a $\mathrm{PO}_{2}>0,3$ e $<20 \%$ ).

Levando-se em consideração o fato de só terem sido isolados em processos infecciosos microrganismos anaeróbios moderados e microaerófilos, conforme os trabalhos de Tally et al. (1977), Willes (1977), Finegold (1977) e Bartlett et al. (1976), no estudo microbiológico das especiarias, somente esses tipos de anaeróbios apresentam real interesse, no que diz respeito a saúde pública.

Jürgensen e Jürgensen (1974), verificaram uma alta incidência de clostrídios sulfito-redutores em mortadela (embutido) vendida a granel na cidade de Niterói, sendo que um dos fatores que poderia ser atribuído para a contaminação do produto são os condimentos vegetais a ele incorporados.

Nickerson e Sinskey (1972), responsabilizam o Clostridium perfringens por vários surtos de toxinfecção alimentar envolvendo principalmente produtos cárneos, além da referência de que as cepas capazes de determinar a toxinfecção, possam ser encontradas no solo, água, alimentos, pó, especiarias, trato intestinal do homem e outros animais no que concorda Jay (1973).

Krishnaswamy et al. (1971), fazem referência à presença de várias estirpes de microrganismos (coliformes, cogumelos, Clostridium perfringens, etc...), e ressaltam a incidência de mesófilos putrefativos em condimentos simples e misturados.

\footnotetext{
* Professor Titular do Depto de Tecnologia dos Alimentos da Faculdade de Veterinária da Universidade Federal Fluminense. Rua Vital Brazil Filho, 64 - Niterói - RJ - CEP 24230-340

** Professor Adjunto do Depto de Tecnologia dos Alimentos - UFF

*** Médico Veterinário do Depto de Tecnologia dos Alimentos - UFF
} 
Masson (1978), analisando 50 amostras comerciais de especiarias (pimenta branca; cayena e preta; pimentão) visando o controle microbiológico de qualidade, isolou, entre outros microrganismos, coliformes, cogumelos e Clostridium Derfringens.

Powers et al. (1975), ao desenvolverem um estudo microbiológico de várias espécies de condimentos vegetais (pimenta; orégano; mostarda) encontraram uma incidência de 15\% para Clostridium perfringens.

Os primeiros passos objetivando a criação de padrão para condimentos foram dados pelo Ministério da Saúde através da Comissão Nacional de Normas e Padrões para Alimentos (CNNPA) que fixa para os mesmos: "Ausência de salmonelas em 25g e no máximo aus/1g de bactérias do grupo coliforme de origem fecal", sem demonstrar, no entanto, qualquer preocupação com outros tipos de microrganismos, talvez tão ou mais importantes que os assinalados.

Reforçam a importância deste fato, trabalhos como o de Ribeiro (1974), onde, ao citar padrões microbiológicos para alimentos portugueses, inclui entre eles os de condimentos desidratados, mencionando para os mesmos, entre outros, os referentes a microrganismos anaeróbios: "Esporos de clostrídios sulfito-redutores $\left(44^{\circ} \mathrm{C}\right)$ ausentes em $0,1 \mathrm{~g}$; Clostridium nigrificans ausente em $2 \mathrm{~g}$ e Clostridium thermosaccharolyticum ausente em $2 \mathrm{~g}$."

O presente trabalho visou pesquisar a presença de clostrídios de importância em saúde pública encontrados nos condimentos utilizados na elaboração de embutidos cárneos, uma vez que todo microrganismo capaz de se multiplicar num hospedeiro pode nele produzir infecção. Ainda compõe o objetivo da pesquisa a identificação de espécies do gênero Clostridium isoladas a partir dos condimentos usados na produção de embutidos cárneos, pela possibilidade de determinar processos infecciosos resultantes da colonização no trato intestinal de consumidores de produtos por eles contaminados (Gravenitz, 1977 e Finegold, 1977). A presença dos clostrídios tem valor também do ponto de vista higiênico-sanitário, uma vez que estes microrganismos são considerados indicadores de contaminação fecal.

Devemos ressaltar ainda o aspecto médico envolvido, em conseqüência dos prováveis microrganismos presentes, na condição de "oportunistas", os quais podem determinar quadros clínicos diversos na dependência direta de alterações do mecanismo antimicrobiano do hospedeiro ou pelo maior potencial de agressão que possuem, ou pela provável contribuição para determinarem intoxicações alimentares.

\section{Material e Métodos}

As amostras analisadas (pimenta branca, louro, canela, noz-moscada, cominho, alho, cebola, orégano, coentro, pimenta preta), estavam acondicionadas em embalagens plásticas hermeticamente fechadas e foram colhidas em diferentes estabelecimentos comerciais. Os condimentos vegetais eram inicialmente identificados quanto ao tipo (natureza da especiaria), aspecto físico (pó) e outras características como marca e procedência.
Em condições de assepsia, eram pesadas vinte gramas da amostra, sendo transferida para um homogeneizador, onde com $200 \mathrm{ml}$ de solução diluente, era submetida à velocidade máxima pelo tempo de dois minutos, com a finalidade de promover a dispersão das bactérias aí presentes. Dando seqüência, $200 \mathrm{ml}$ eram submetidos a centrifugação de 1000 rpm durante cinco minutos para promover a sedimentação dos materiais mais grosseiros presentes na suspensão. Após este período, $80 \mathrm{ml}$ do sobrenadante eram colhidos e transferidos para os tubos de centrífuga onde eram submetidos a 3.000 rpm durante quinze minutos, com objetivo de precipitar as bactérias presentes. Em seguida, $60 \mathrm{ml}$ do sobrenadante obtido eram desprezados com a finalidade de concentrar o material a 4:1 (título final), correspondendo a percentagem de $40 \%$.

Do concentrado ressuspenso eram obtidas duas alíquotas de $10 \mathrm{ml}$. Uma das quais era aquecida à temperatura de $80^{\circ} \mathrm{C}$ por dez minutos, com resfriamento imediato em banho de água gelada. A outra porção não era submetida a tratamento térmico.

Semeamos a razão de $5 \mathrm{ml}$ para cada $10 \mathrm{ml}$ de meio de cultura apropriado e concentrado, Agar Sangue (Holdeman et al. 1977) e SPS - Sulfito Polimixina Sulfadiazina - agar modificado (Angellotti et al. 1962, citado por BBL, 1967), onde realizamos a substituição da solução original de

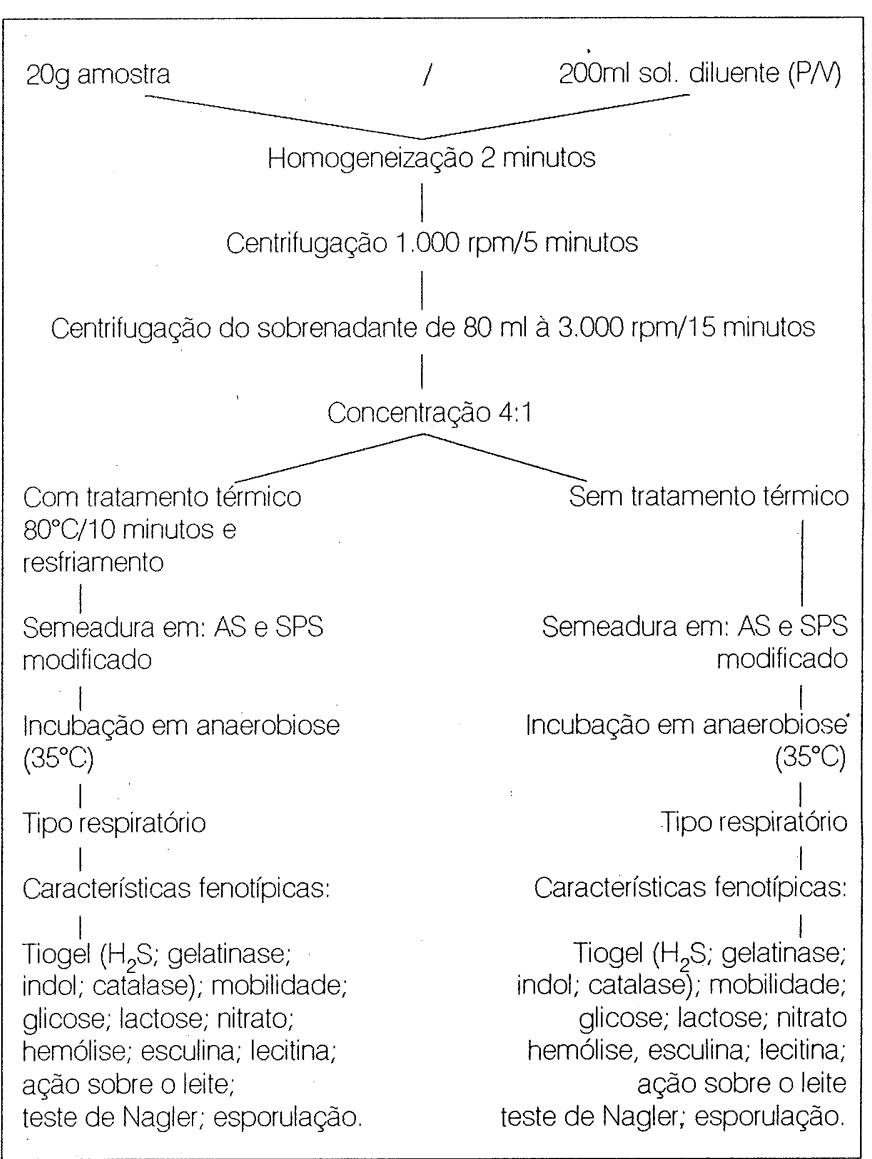

Fig. 1 - Metodologia de isolamento e indentificação dos clostrídios 
antimicrobianos (polimixina e sulfadiazina) por uma solução a $0,14 \%$ de sulfato de neomicina acrescentando $0,5 \mathrm{ml}$ de solução em $10 \mathrm{ml}$ de meio (SPS), resultando no final a semeadura de quatro placas, duas da subamostra aquecida e duas não tratadas pelo calor. A condição de anaerobiose era conseguida, para incubação das placas, pelo sistema da passivação do cobre, descrito por Jürgensen e Jürgensen (1982). Os repiques das UFCs (Unidades Formadoras de Colônias) isoladas eram feitos para o caldo Tioglicolato 135-C, (Holdeman et al. 1977). A partir deste tubo, após a verificação das características morfo-tintoriais através de esfregaço corado pelo método de Gram de Kopellof-Beerman (Holdeman et al. 1977), promovidos averificação do tipo respiratório seguindo a orientação de Prevot (1959). A identificação dos anaeróbios isolados foi executada tomando-se por base o método descrito pelo manual do "Virginia Polytechnic Institute", (Holdeman, et al. 1977) e o descrito por Jürgensen e Jürgensen (1982), onde realizamos as seguintes provas bioquímicas: $\mathrm{H}_{2} \mathrm{~S}$; gelatina; indol; catalase; mobilidade; glicose; lactose; nitrato; hemólise; esculina; lecitina; ação sobre o leite; teste de Nagler, conforme o esquema descrito (Fig. 1). Além das provas bioquímicas citadas, como complementação das características fenotípicas trabalhadas, realizamos testes para a verificação da capacidade de esporulação dos microrganismos do gênero Clostridium, assim como, a constatação da presença de esporos pela coloração de Wirtz - Conklin (Finegold et al., 1982, e Duncan e Strong, 1968). Quando não ocorria a visualização de esporos, submetíamos duas porções da mesma cultura, a tratamentos térmicos distintos $\left(80^{\circ} \mathrm{C}\right.$ por 5 minutos e $70^{\circ} \mathrm{C}$ durante 10 minutos) com semeadura subsequente em caldo tioglicolato suplementado.

\section{Resultados}

Os resultados obtidos para o exame microbiológico qualitativo realizado em diferentes condimentos vegetais (especiarias) mostraram uma incidência da ordem de 65,7\% de espécies do gênero Clostridium em 35 amostras analisadas conforme a Tabela 1 e Tabela 2. É importante mencionar que os achados relacionam-se a $2 \mathrm{~g}$ do material original semeado. Em conformidade corn a metodologia de isolamento e identificação dos clostrídios citada anteriormente foram isoladas e identificadas, pelas características fenotípicas, as seguintes espécies nas amostras correspondentes: Pimenta branca (Clostridium perfringens; Clostridium alycolicum; Clostridium butyricum); Iouro (Clostridium berfringens): noz-moscada (Clostridium perfringens; Clostridium ramosum); cominho (Clostridium perene;

Tabela 1 - Percentagem de microrganismos do gênero Clostridium isolados das amostras de condimentos vegetais

\begin{tabular}{ccc}
\hline $\begin{array}{c}\text { número de } \\
\text { amostras } \\
\text { (total) }\end{array}$ & gênero Clostridium & $\begin{array}{c}\text { não pertencentes } \\
\text { ao gênero } \\
\text { Clostridium }\end{array}$ \\
\hline 35 & $65,7 \%$ & $34,3 \%$ \\
\hline
\end{tabular}

Clostridium glycolicum; Clostridium barati); alho (Clostridium perene; Clostridium perfringens); cebola (Clostridium glycolicum: Clostridium paraputrificum; Clostridium perfringens): orégano (Clostridium acetobutylicum; Clostridium glycolicum; Clostridium ramosum); coentro (Clostridium perfringens; Clostridium glycolicum); pimenta preta (Clostridium felsinium; Clostridium sporogenes).

\section{Discussão e Conclusões}

O estudo de anaeróbios em condimentos é de capital importância considerando-se a ocorrência de intoxicações alimentares envolvendo a participação do Clostridium perfringens (Sinnel, 1981), e as alterações provocadas no alimento (deterioração) ou da implantação de germes oportunistas no organismo do consumidor.

A microbiota anaeróbia necessita de potencial redox (Eh) negativo para favorecer seu desenvolvimento, porém o Eh dos vegetais, entre eles, o das especiarias, apresenta valores positivos (Jay, 1973), indicando que estes condimentos vegetais não se constituem um "habitat" favorável ao desenvolvimento destes microrganismos. Considerando-se tais aspectos e a presença de substâncias antimicrobianas, com ação bacteriostática ou bactericida em especiarias, a evidenciação de anaeróbios do gênero Clostridium foi comprovada experimentalmente, sugerindo que a ação antimicrobiana natural das amostras analisadas não foi efetiva sobre o germe em estudo e que o baixo Eh e dessecação dos condimentos não foram suficientes para tórná-lo inviável.

O Clostridium perfringens apresentou uma alta taxa de isolamento, cerca de $37,4 \%$, o que está en concordância com a cifra de $42 \%$ fornecida por Masson (1978), ao analisar especiarias. Tais achados, no entanto, diferem do percentual relativamente baixo de $15 \%$ para este tipo de microrganismo encontrado por Powers et al. (1975), nestes condimentos vegetais.

Krishnawany et al. (1971), faz citação do isolamento de Clostridium perfringens em condimentos simples e misturados, sem fornecer seus percentuais. A importância que reveste a presença de Clostridium perfringens, deve encontrar maior valorização no tocante ao controle de produtos de origem animal, tendo por base a afirmação de Nickerson e Sinskey (1972), que atribui o fato de ter sido ele responsabilizado por vários surtos de intoxicação alimentar, envolvendo principalmente produtos cárneos, além da referência de que as cepas capazes de determinar a intoxicação poderem ser encontradas no solo, água, alimentos, pó, especiarias, trato intestinal do homem e outros animais, (Jay 1973). Considerando-se o fato de que para a ocorrência da intoxicação necessitamos de um número relativamente alto de bactérias, cerca de 109/g, tomando-se por base os nossos achados e a afirmativa de Jay, (1973), os condimentos podem contribuir para um aumento significativo desses microrganismos nos produtos cárneos embutidos onde são adicionados rotineiramente.

Nickerson e Sinskey, 1972; Krishnaswamy et al. 1971; Powers et al. 1975 mostram a incidência de percentuais variáveis de clostrídios em especiarias e que a maior parte 


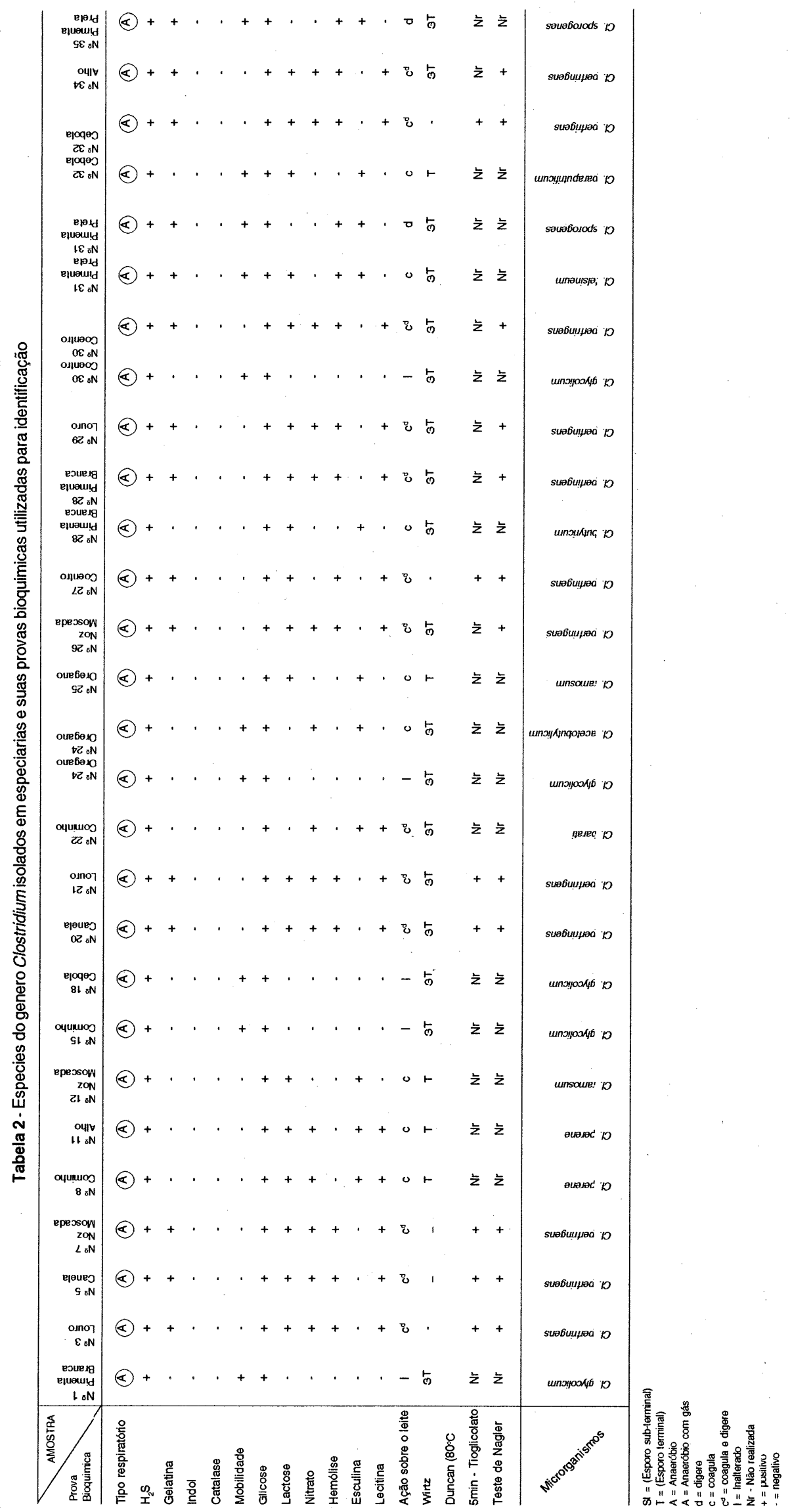


daqueles envolvidos na contaminação de produtos cárneos pertence ao grupo de clostrídios sulfito-redutores, concluindo-se que nos produtos onde os condimentos vegetais são incorporados, podem funcionar como uma provável fonte de veiculação destes microrganismos.

A nossa legislação, no que se refere aos padrões microbiológicos que norteiam as características microbiológicas dos condimentos, não menciona, nem qualitativa nem quantitativamente padrões referentes aos clostrídios.

A metodologia usada no alimento de Clostridium procurou reproduzir as condições encontradas "in vivo", atendendo as suas exigências nutricionais e de temperatura ótima de crescimento, uma vez que o homem pode ser usado como "habitat" pelo microrganismo.

A adição de condimentos em produtos de origem animal tem como objetivo ressaltar o sabor dos produtos, estimular as glândulas salivares e a produção de sucos gástricos, entretanto se estes estiverem contaminados por microrganismos saprofíticos e/ou potencialmente patogênicos, podem reduzir o prazo de vida comercial destes produtos e/ou determinar perdas econômicas e colocar em risco a saúde do consumidor. Levando-se em consideração, estes fatos, concluímos que $65,7 \%$ das amostras analisadas, não deveriam ser incorporadas em produtos de origem animal tendo por base os aspectos ligados à Medicina Veterinária Preventiva, o controle microbiológico de qualidade e a inspeção de P.O.A., uma vez que se encontravam contaminadas por diferentes espécies do gênero Clostridium potencialmente capazes de determinar quadros nosológicos aos ingestores.

\section{Summary}

\section{Clostridium of vegetable spices utilized in sausages}

Using methodology recommended by Holdeman et al. (1977) and Jürgensen and Jürgensen (1982), microorganisms of the genus Clostridium were isolated from thirtyfive vegetal species utilized in sausage. Clostridium was seen in $65,7 \%$ of the samples analysed. The following microorganisms (identied based on phenotypical characteristics) and corresponding vegetal samples were: white pepper... (Clostridium glycolicum; Clostridium butyricum; Clostridium Derfringens), laurel (Clostridium perfringens), Cinammon (Clostridium perfringens), Nutmeg (Clostridium ramosum; Clostridium perfringens); Cummin (Clostridium perene; Clostridium glycolicum; Clostridium barati), Garlic (Clostridium perfringens; Clostridium perene), Onion (Clostridium Derfringens; Clostridium glycolicum; Clostridium paraputrificum), Origanum (Clostridium ramosum: Clostridium glycolicum; Clostridium acetobutyricum), Coentro
(Clostridium perfringens; Clostridium glycolicum), Black pepper (Clostridium felsineum and Clostridium sporogenes).

Key words: Clostrideos Spice Sausage

\section{Referências Bibliográficas}

BBL Manual of Products and Laboratory Procedures. 5 ed. Maryland; Division of Becton Dickson and Co., 1967. 213p.

BARTLEIT, J.G.; SULLIVAN, N.; SIGLER, T.J.L. Anaerobes survive in clinical specimens despite delayed processing. J. Clin. Microbiol, v. 3, p. 133136, 1976.

BRASIL, MINISTÉRIO DA AGRICULTURA. Departamento Nacional de Inspeção de Produtos de Origem Animal. Regulamento de Inspeção Industrial e Sanitária de Produtos de Origem Animal. Aprovado pelo Decreto $n^{\circ} 30.691$ de 29 de março de 1953 alterado pelo Decreto $n^{c}$ 1.225 de 25 de junho de 1962, Rio de Janeiro, 1962. 364p.

DUNCAN, C.L., STRONG, D.H. Improved medium for sporulation of Clostridium perfringens. Appl. Microbiol., v. 16, p. 82-89, 1968.

FINEGOLD, S.M. Anaerobic bacteria in human disease. New York: Academic Press, 1977, 167p

FINEGOLD, S.M., MARTIN, W.J. Bailey Scott's diagnostic micro biology. 6 ed. London: C.V. Mosby, 1982, 213p.

GRAEVENITZ, A.V. The Role Opportunistic Bacteria in Human Disease. Ann Rev. Microbiol, v. 31, p. 447-471, 1977.

HOLDEMAN, L.V.; CATO, E.P.; MORE, W.E.C. Anaerobic Laboratory Manual. 4 ed. Blacksburg: Virginia Polytecnic Institute and State University, $1977,308 \mathrm{p}$

JAY, J.M. Microbiologia moderna de los alimentos. Zaragoza, Acribia, 1973, 319p.

JÜRGENSEN, L.D., JÜRGENSEN, C.A. Contagem de clostrídios sulfito redutores em carne e derivados na cidade de Niterói-RJ. In: Congresso Brasileiro de Microbiologia, 5, 1974, Rio de Janeiro. Anais. Rio de Janeiro: Universidade Gama Fitho, 1974, v. 1, p. 30-51.

JÜRGENSEN, L.D., JÜRGENSEN, C.A. Pesquisa de bactérias anaeróbias clinicamente significantes. In: Congresso Brasileiro de Patologia Clinica, 16, 1982. Rio de Janeiro. Anais. Rio de Janeiro: 1982. v. 1, p. 49-71.

KRISHNASWAMY, M.A., PATEL, J.D., PARTHASARATHY, N. Enemeration of microrganisms in spices and spice mixtures. Journal of Food Science and Technology, v. 8, n. 4, p. 191-194, 1971.

MASSON, A. Hygienic Quality os Spices. Mitteilungen aus Demgebiete der Lebensmitte Putersuchung um Hygiene, 69, n. 4, p. 544-549, 1978.

NICKERSON, J.T., SINSKEY, A.J. Microbiology of Foods and Food Processing. New York: American Elsevier, 1972. 278p.

POWER, E.M., LAWYER, R., MASUOKA, Y. Microbiology of Processed Spices. Journal of Milk and Food Technology, v. 38, n. 11, p. 683-687, 1975.

PREVOT, A.R. Techniques pourle diagnostic des bacterias anaerobies Seine: La Tourella, 1959, 164p.

RIBEIRO, A.M.R. Padrões bacteriológicos de alimentos portugueses. Rev. Microbiol., São Paulo, v. 5, n. 1, p. 17-25, 1974.

SINELL, H.J. Introduction a la hygiene de los alimentos. Zaragoza: Acribia, $1981,167 p$.

TALLY, F.P., GOLDIN, B.R., JACOBUS, M.V. Superoxide dismutase in anaerobic bacteria of clinical significance infect immun. J. Clin. Microbiol, v. 16, n. 1, p. 20, 1977.

WILLES, A.T. Anaerobic bacteriology: Clinical and Laboratory practice, 3 ed. London: Butterworths, 1977, 6p. 